\title{
Relative Strength of Noncovalent Interactions and Covalent Backbone Bonds in Gaseous RNA-Peptide Complexes
}

\author{
Jovana Vušurović and Kathrin Breuker*(i)
}

Institut für Organische Chemie and Center for Molecular Biosciences Innsbruck (CMBI), Universität Innsbruck, Innrain 80-82, 6020 Innsbruck, Austria

\section{Supporting Information}

ABSTRACT: Interactions of ribonucleic acids (RNA) with basic ligands such as proteins or aminoglycosides play a key role in fundamental biological processes. Native top-down mass spectrometry (MS) has recently been extended to binding site mapping of RNA-ligand interactions by collisionally activated dissociation, without the need for laborious sample preparation procedures. The technique relies on the preservation of noncovalent interactions at energies that are sufficiently high to cause RNA backbone cleavage. In this study, we address the question of how many and what types of noncovalent interactions allow for binding site mapping by top-down MS. We show that proton transfer from protonated ligand to deprotonated RNA within salt bridges initiates loss of the ligand, but that proton transfer becomes energetically unfavorable in the presence of additional hydrogen bonds such that the noncovalent interactions remain stronger than the covalent RNA backbone bonds.

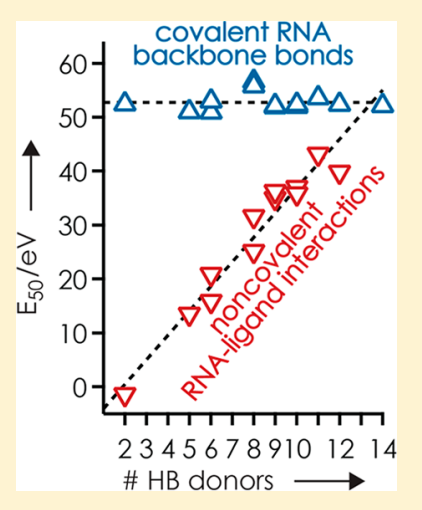

$\mathrm{N}$

ative mass spectrometry (MS) is an evolving technique $^{1-3}$ for the study of biomolecular complexes that relies on the retention of noncovalent interactions during and after solvent removal by electrospray ionization (ESI). If, to what extent, and on what time scale biomolecular structure can be preserved after transfer into the gas phase has become an active field of research. ${ }^{4-8}$ Solvent removal on its own can cause structural changes as it alters the strength of noncovalent interactions, ${ }^{4}$ and native "top-down" MS approaches ${ }^{9-18}$ employ various dissociation techniques by which the energy of the biomolecular complexes is increased. The kind of information that can be obtained in native top-down MS experiments thus critically depends on the relative stability of noncovalent interactions and covalent bonds: If the latter are more stable, complex composition and stoichiometry can be revealed, whereas if the former are more stable, binding sites and primary structure can be determined. ${ }^{3}$ The cleavage of covalent bonds while preserving noncovalent interactions seems counterintuitive, especially when slow heating methods such as collisionally activated dissociation (CAD) are used. Nevertheless, a number of gas-phase studies have demonstrated that noncovalent bonds can be stronger than covalent bonds. ${ }^{10,18-22}$

For example, we have recently shown that the electrostatic interactions between TAR ribonucleic acid (RNA) and a peptide comprising the arginine-rich binding region of tat protein are sufficiently strong in the gas phase to survive RNA backbone bond cleavage by $\mathrm{CAD}$, thus allowing its use for probing tat binding sites in TAR RNA. ${ }^{10} \mathrm{X}$-ray crystallography $^{23}$ and solution $\mathrm{NMR}^{24}$ were so far unsuccessful in providing a detailed picture of the TAR-tat binding interface, but highly converging structures of TAR RNA in a complex with a cyclic tat peptide mimetic showed interactions of all basic residues with phosphodiester moieties ${ }^{25}$ and excellent agreement with the binding site predicted from our MS data. ${ }^{10}$ At the solution $\mathrm{pH}$ of 7.7 used in our study, the arginine $(\mathrm{pK}>$ $11)^{26}$ and lysine $(\mathrm{pK}>10.5)^{26,27}$ side chains of tat peptide should be protonated and available for salt bridge (SB) formation with the deprotonated RNA phosphodiester moieties $(\mathrm{pK} 1-3) .{ }^{28}$ We attributed the unusual strength of TAR-tat interactions in the gas phase to electrostatic interactions, of which salt bridges are thought to provide the highest contribution to stability. ${ }^{20,29}$ However, the question remains as to how many and what types of interactions, alone or in combination, are sufficient for probing of RNA-ligand binding sites by CAD.

Thermodynamic information for noncovalent interactions of small gaseous complexes has been determined with high accuracy, ${ }^{30,31}$ but it is challenging, if not impossible, to obtain data for larger systems in which the strength of individual neutral $(10-40 \mathrm{~kJ} / \mathrm{mol})^{30,32,33}$ and ionic $(20-170 \mathrm{~kJ} /$ $\mathrm{mol})^{30,33}$ hydrogen bonds $(\mathrm{HB})$ is modulated by other charges and noncovalent bonds. Likewise, the stability of salt bridges between protonated basic (e.g., arginine side chains) and deprotonated acidic (e.g., RNA phosphodiester moieties) sites is strongly affected by the number and distribution of other charges and the hydrogen-bonding network. Williams and coworkers recently found that this is the case even for small complexes: As a result of differing hydrogen bond networks and net charges, glycine dimer anions and cations have SB and

Received: November 21, 2018

Accepted: December 26, 2018

Published: January 7, 2019 
HB interfaces, respectively. ${ }^{34}$ Here, we have studied the relative strength of noncovalent and covalent bonds in gaseous RNA-ligand complexes formed by association reactions in solution and ESI. ${ }^{35}$ Seven peptides (GR, VR, DR, ER, KR, RR, NGR) and the fixed-charge ligand tetramethylammonium (Tma) were investigated in 1:1 complexes with seven different RNAs (Table 1).

\section{Table 1. RNAs Studied}

\begin{tabular}{cccc} 
RNA & sequence & possible hairpin structure & $\# \mathrm{~A}, \mathrm{G}, \mathrm{C}, \mathrm{U}$ bases \\
$\mathbf{1}$ & GGCUAGCC & yes & $1,3,3,1$ \\
$\mathbf{2}$ & AAUCGAUU & yes & $3,1,1,3$ \\
$\mathbf{3}$ & GGGAUCCC & yes & $1,3,3,1$ \\
$\mathbf{4}$ & AAAGCUUU & yes & $3,1,1,3$ \\
$\mathbf{5}$ & CAGACUGU & no & $2,2,2,2$ \\
$\mathbf{6}$ & ACUGCUAG & no & $2,2,2,2$ \\
7 & CUCUCUCU & no & $0,0,4$ \\
\hline
\end{tabular}

\section{EXPERIMENTAL SECTION}

Experiments were performed on a $7 \mathrm{~T}$ Fourier transform ion cyclotron resonance mass spectrometer (Bruker, Austria) equipped with an ESI source, a linear quadrupole for ion isolation, and a collision cell through which a flow of Ar gas $(0.2 \mathrm{~L} / \mathrm{s}$ except when indicated otherwise) was maintained for CAD. ${ }^{36}$ RNA-ligand complexes were electrosprayed $(1.5 \mu \mathrm{L} /$ $\min )$ from solutions of RNA $(1 \mu \mathrm{M})$ and ligand $(5-100 \mu \mathrm{M})$ in $1: 1 \mathrm{CH}_{3} \mathrm{OH} / \mathrm{H}_{2} \mathrm{O}$ at $\mathrm{pH} \sim 7.5$, adjusted by the addition of piperidine and imidazole $\left(\sim 1.3 \mathrm{mM}\right.$ each). $\mathrm{CH}_{3} \mathrm{OH}$ was highperformance liquid chromatography grade (Acros, Vienna, Austria) and $\mathrm{H}_{2} \mathrm{O}$ was purified to $18 \mathrm{M} \Omega \cdot \mathrm{cm}$ using a Milli-Q system (Millipore, Austria). Dipeptide acetate salts were from Bachem (Bubendorf, Switzerland) and NGR and RNAs 2-7 from Sigma-Aldrich (Vienna, Austria), and used without further purification. RNA 1 was prepared by solid-phase synthesis and desalted as described in ref 37 . According to theoretical predictions (http://rna.tbi.univie.ac.at/cgi-bin/ RNAWebSuite/RNAfold.cgi), ${ }^{38}$ RNAs 1-7 should not form any stable secondary structures in solution, especially at the high methanol content used. However, RNAs 1-4 could potentially form hairpin structures in the presence of ligands. ${ }^{35}$ The $\mathrm{CAD}$ experiments were performed over a period of 18 months, and we did not observe any correlation between the order of experiments and the collision energy required for dissociation of the RNA or RNA-ligand complexes. Between 50 and 100 scans were added for each spectrum.

\section{RESULTS AND DISCUSSION}

Figure 1 shows the yield of products from $\mathrm{CAD}$ of $(\mathrm{M}-$ $3 \mathrm{H})^{3-},(\mathrm{M}+\mathrm{VR}-3 \mathrm{H})^{3-},(\mathrm{M}+\mathrm{RR}-3 \mathrm{H})^{3-}$, and $(\mathrm{M}+\mathrm{Tma}$ $-4 \mathrm{H})^{3-}$ ions of RNA 1 versus collision energy. In agreement with earlier studies, ${ }^{10,36,39} \mathrm{CAD}$ of the $(\mathrm{M}-3 \mathrm{H})^{3-}$ ions produced predominantly $c$ and $y$ fragments from RNA phosphodiester backbone bond cleavage; at elevated collision energy, $a$ and $w$ fragments from $\mathrm{C}^{3 \prime}-\mathrm{O}$ backbone bond cleavage and internal ( $i$ ) fragments from secondary backbone bond cleavage appeared (Figure S1a). Products from loss of nucleobases and $\mathrm{H}_{2} \mathrm{O}$ from $(\mathrm{M}-3 \mathrm{H})^{3-}$ and fragment ions were also observed (Figure S2a) and included in the calculation of RNA and fragment yields.

Similar products and product yields were observed in CAD of $(\mathrm{M}+\mathrm{Tma}-4 \mathrm{H})^{3-}$ ions of RNA 1 (Figure S1b), although a)

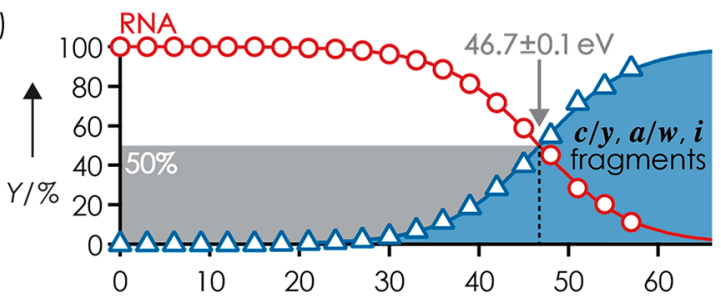

b)

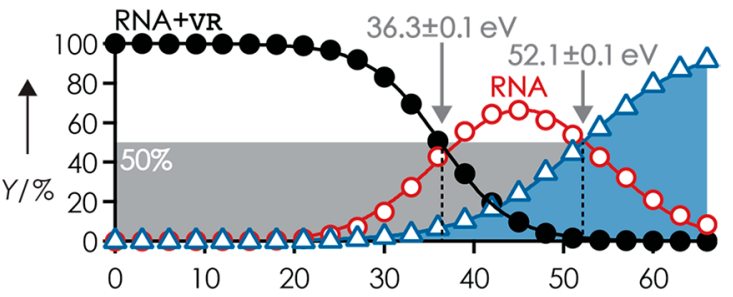

C)

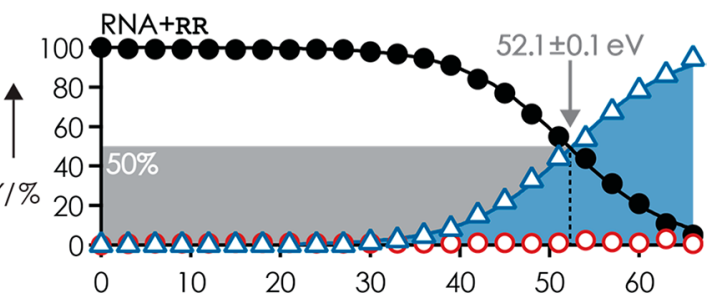

d)

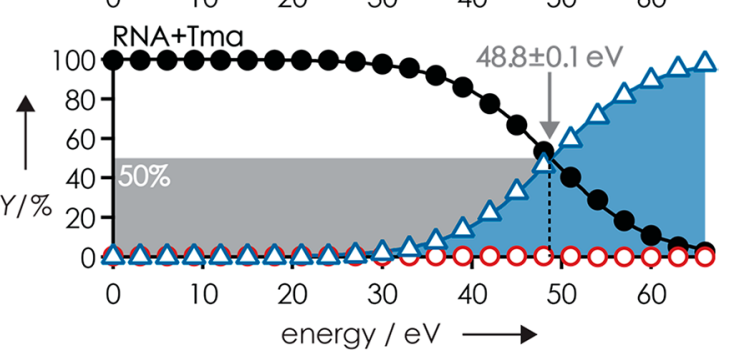

Figure 1. Products from $\mathrm{CAD}$ of $(\mathrm{a})(\mathrm{M}-3 \mathrm{H})^{3-}$, (b) $(\mathrm{M}+\mathrm{VR}-$ $3 \mathrm{H})^{3-}$, (c) $(\mathrm{M}+\mathrm{RR}-3 \mathrm{H})^{3-}$, and $(\mathrm{d})(\mathrm{M}+\mathrm{Tma}-4 \mathrm{H})^{3-}$ ions of RNA 1 versus laboratory-frame collision energy illustrate the competition between covalent RNA backbone bond cleavage into $c / y, a / w$, or $i$ fragments (blue) and noncovalent bond dissociation into free RNA (red) and ligand; energies required for 50\% complex dissociation and 50\% fragment formation are indicated by arrows.

the collision energy required for $50 \%$ fragment formation by breaking of covalent backbone bonds, $E_{50}(c)$, increased by $\sim 5 \%$ from $46.7 \pm 0.1$ to $48.8 \pm 0.1 \mathrm{eV}$ (Figure 1a,d). The increase in $E_{50}(c)$ can be attributed to the $\sim 6 \%$ increase in degrees of freedom (DOF) of the $(\mathrm{M}-3 \mathrm{H})^{3-}$ and $(\mathrm{M}+\mathrm{Tma}$ $-4 \mathrm{H})^{3-}$ ions from 777 to $825 .^{40} \mathrm{CAD}$ produced no free RNA from dissociation of Tma, and no $c_{6}, c_{7}, a_{6}, a_{7}$, or $y_{7}$ fragments ( $w_{7}$ was not observed) without Tma were detected even at the highest collision energy used (Figure S3a). Moreover, none of their complementary fragments, $y_{2}, w_{2}, w_{1}$, and $c_{1}\left(a_{1}\right.$ and $y_{1}$ were not observed), carried Tma. Fragments from cleavage at sites 2-5 showed varying occupancy with Tma (Figure S3b), which suggests binding of Tma to residues 2-5. The occupancy values of $c_{2}$ and $c_{5}$ and their complements $y_{6}$ and $y_{3}$ were relatively constant over the collision energy range in which signal-to-noise ratios of $c$ and $y$ fragments with and without Tma attached were not limited by low yields (below $39 \mathrm{eV}$ ) or secondary backbone bond cleavage (above $57 \mathrm{eV}$ ), and added up to $105 \pm 1 \%$ and $99 \pm 1 \%$ for $c_{2} / y_{6}$ and $c_{5} / y_{3}$, respectively.

By contrast, the occupancy values of $c_{3} / y_{5}$ and $c_{4} / y_{4}$ fragments from cleavage at sites 3 and 4 varied strongly with collision energy, between $\sim 40 \%$ and $\sim 85 \%$, and those from 
cleavage at site 4 added up to $\sim 130 \%$ (Figure S3b). The variation in occupancy values can be attributed to strong binding of Tma to both residues 3 and 4 , and the competition between complementary fragments $\left(c_{3}\right.$ and $y_{5}, c_{4}$ and $\left.y_{4}\right)$ for Tma during fragment separation. Strong binding of Tma to residues 3 and 4 is further indicated by the presence of $C U$ in all internal fragments with Tma attached from $\mathrm{CAD}$ at the highest collision energy used $(66 \mathrm{eV}): i($ GCUA + Tma), $i(\mathrm{GCU}+\mathrm{Tma})$, and $i(\mathrm{CUA}+\mathrm{Tma})$. The added occupancy values $>100 \%$ likely result from the lower stability against secondary backbone cleavage of fragments without ligand attached compared to that of fragments with ligand attached. ${ }^{10}$ From the fact that no free RNA and even internal fragments with Tma attached were observed in CAD of $(M+$ Tma $4 \mathrm{H})^{3-}$ ions of RNA 1 , we conclude that the noncovalent bonds between Tma and the RNA are far stronger than the covalent backbone bonds of the RNA. This order is consistent with the calculated interaction energy between gaseous Tma and dimethylphosphate of $355 \mathrm{~kJ} / \mathrm{mol}^{41}$ and the energies for hydrolysis of dimethylphosphate by $\mathrm{H}_{2} \mathrm{O}^{42}$ and $2^{\prime}, 3^{\prime}$-ribose cyclic phosphate by $\mathrm{CH}_{3} \mathrm{OH}^{43}$ attack on the phosphorus atom of $\sim 190$ and $\sim 225 \mathrm{~kJ} / \mathrm{mol}$, respectively.

The breakdown curves of the $(M+R R-3 H)^{3-}$ ions of RNA 1 were highly similar to those of the $(\mathrm{M}-3 \mathrm{H})^{3-}$ and $(\mathrm{M}$ + Tma $-4 \mathrm{H})^{3-}$ ions (Figure 1 ); again, CAD produced no significant yields of free RNA at any of the collision energies used. The $E_{50}(c)$ of $52.1 \pm 0.1 \mathrm{eV}$ was $\sim 12 \%$ higher than that for $(\mathrm{M}-3 \mathrm{H})^{3-}$, which is close to the $\sim 16 \%$ increase in DOF of the $(\mathrm{M}-3 \mathrm{H})^{3-}$ and $(\mathrm{M}+\mathrm{RR}-3 \mathrm{H})^{3-}$ ions from 777 to 924. However, the yield of $c$ and $y$ fragments with RR attached was lower by a factor of $\sim 0.7$ than that for Tma (Figure S4), which indicates RR dissociation from the fragments at elevated collision energy. In support of this hypothesis, the added occupancy of $c$ and $y$ fragments with RR decreased with increasing collision energy (Figure S5). The lower stability of the noncovalent interactions between $\mathrm{RR}$ and the $c, y$ fragments compared to that of Tma can be attributed to proton transfer (PT) within intermolecular salt bridges. In a recent CAD study of RNA 1 in complexes with guanidine or guanidine derivatives including $\mathrm{R}$, we found that $\mathrm{PT}$ from protonated ligand (L) to a deprotonated phosphodiester moiety of the RNA, which converts the intermolecular salt bridge into a far weaker hydrogen bond, generally preceded ligand dissociation. ${ }^{35}$ Likewise, PT from a protonated guanidinium group of $\mathrm{RR}$ to a deprotonated phosphodiester moiety of a $c$ or $y$ fragment should precede loss of RR. However, protonated RR has a zwitterionic structure in the gas phase $^{44}$ (Scheme 1) and can form two salt bridges with the RNA, such that transfer of two protons is required for SB to $\mathrm{HB}$ conversion. The higher stability of the noncovalent

Scheme 1. Structures of Gaseous (a) Tma, (b) $(\mathbf{R R}+\mathbf{H})^{+},{ }^{44}$ and $(\mathrm{c})(\mathrm{VR}+\mathrm{H})^{+44}$<smiles></smiles>

interactions of the $(M+R R-3 H)^{3-}$ ions over that of the complexes of RNA 1 with guanidine or its derivatives, all of which dissociated at collision energies below that required for covalent RNA backbone cleavage into $c$ and $y$ fragments, ${ }^{35}$ is consistent with higher energy requirements for transfer of two instead of one proton. Finally, the higher stability of the noncovalent interactions of Tma with RNA 1 compared to those of RR is consistent with a far higher proton affinity (PA) of deprotonated Tma (which is the corresponding, overall neutral base of Tma) compared to that of RR. This data suggests that the electrostatic energy between the positively charged ligands and deprotonated RNA is high enough to prevent ligand dissociation during $\mathrm{CAD}$ unless $\mathrm{PT}$ from ligand to RNA occurs.

The peptide ligands other than RR showed weaker binding to RNA 1 (Figure S6), and besides fragments from RNA backbone cleavage, $\mathrm{CAD}$ also produced free RNA as illustrated for VR in Figure 1b. Just like in our previous study, ${ }^{35}(\mathrm{M}-$ $4 \mathrm{H})^{4-}$ RNA ions were not observed in CAD of the complexes with a net charge of -3 , consistent with $\mathrm{PT}$ from protonated ligand to the RNA prior to ligand dissociation. The collision energy required for $50 \%$ ligand dissociation by breaking of noncovalent bonds, $E_{50}(n c)$, in CAD of the $(\mathrm{M}+\mathrm{VR}-3 \mathrm{H})^{3-}$ ions was $36.3 \pm 0.1 \mathrm{eV}$, and the collision energy required for $50 \%$ fragment formation by breaking of covalent bonds, $E_{50}(c)$, was $52.1 \pm 0.1 \mathrm{eV}$. Thus, for $\mathrm{VR}, E_{50}(n c)$ is $69.6 \pm 0.2 \%$ of $E_{50}(c)$. Furthermore, we found that increasing the rate of $\mathrm{Ar}$ gas flow through the collision cell $^{36}$ by $50 \%$, from 0.2 to $0.3 \mathrm{~L} /$ s, only slightly increased both $E_{50}(n c)$ (by $3 \%$, from $36.3 \pm 0.1$ to $37.4 \pm 0.1 \mathrm{eV}$ ) and $E_{50}(c)$ (by $4 \%$, from $52.1 \pm 0.1$ to 54.1 $\pm 0.1 \mathrm{eV})$, but $E_{50}(n c)$ in $\%$ of $E_{50}(c)$ was, within error limits, the same at $0.3 \mathrm{~L} / \mathrm{s}(69.2 \pm 0.2 \%)$ and $0.2 \mathrm{~L} / \mathrm{s}(69.6 \pm 0.2 \%)$. Accordingly, small fluctuations in Ar gas flow rate (on the order of a few percentage points), and thus partial Ar pressure in the collision cell, should not significantly affect $E_{50}(n c)$, $E_{50}(c)$, or $E_{50}(n c)$ in \% of $E_{50}(c)$.

The $E_{50}(c)$ values for all ligands (Figure $2 \mathrm{a}$ ), including those for the guanidine ligands from our previous study, ${ }^{35}$ showed little variation (average $52.8 \mathrm{eV}$, standard deviation $\pm 1.7 \mathrm{eV}$ ) that can in part be attributed to differences in the number of DOF of the complexes (Figure S7, Table S1). By contrast, the $E_{50}(n c)$ values varied strongly, between -1.4 and $43.2 \mathrm{eV}$, which is up to $81 \%$ of the corresponding $E_{50}(c)$ values (Figure 2 ). The only ligand PA values available (tmeGnd, $1032 \mathrm{~kJ} /$ $\mathrm{mol}$; Gnd, $986 \mathrm{~kJ} / \mathrm{mol} ; \mathrm{R}, 1051 \mathrm{~kJ} / \mathrm{mol})^{45}$ did not correlate with complex stability, the order of which (tmeGnd < Gnd < $\mathrm{R})$ cannot be attributed to differences in the number of DOF of the complexes either (tmeGnd, 843; Gnd, 798; R, 855). ${ }^{35}$ However, the $E_{50}(n c)$ values increased linearly with the number of hydrogen bond donors of the ligands (Figure 2, Scheme S1). $E_{50}(n c)$ values for GR, VR, DR, and ER were similar, which suggests that the side chain carboxylic acid functionalities were not involved in RNA-ligand binding. This hypothesis is supported by extensive loss of $\mathrm{H}_{2} \mathrm{O}$ loss ${ }^{46,47}$ from $(\mathrm{M}+\mathrm{DR}-3 \mathrm{H})^{3-}$ and $(\mathrm{M}+\mathrm{ER}-3 \mathrm{H})^{3-}$ ions (Figure S8). For ligands with the same number of $\mathrm{HB}$ donor atoms (Gnd/ Gpa, aGpa/R, GR/VR, DR/ER), $E_{50}(n c)$ values of the ligands with the longer alkyl chain (Gpa, R, VR, ER) were consistently higher, suggesting that both inductive effects on PA and conformational flexibility alter complex stability. However, these effects are far smaller than that of the number of $\mathrm{HB}$ donor atoms (Figure 2). 


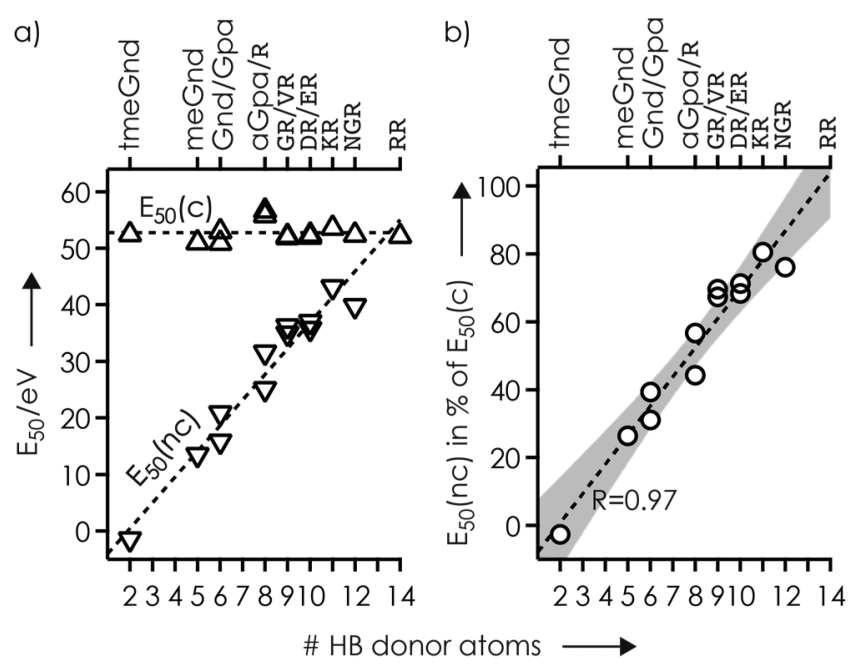

Figure 2. (a) Collision energy required for $50 \%$ complex dissociation by cleavage of noncovalent bonds $\left(E_{50}(n c), \nabla\right)$ and for $50 \%$ fragment formation by cleavage of covalent RNA backbone bonds $\left(E_{50}(c), \triangle\right)$ in CAD of complexes with RNA 1 and net charge of -3 , and (b) $E_{50}(n c)$ in \% of $E_{50}(c)$, versus the number of $\mathrm{HB}$ donor atoms of the ligands; lines are linear fit functions and the gray area in (b) illustrates the $99 \%$ confidence interval.

The $E_{50}$ values here are from $\mathrm{CAD}$ experiments under multiple-collision conditions, and calibration of the laboratoryframe collision energy scale to an internal energy scale is not straightforward. ${ }^{36,48,49}$ Nevertheless, because all complexes were studied under the same experimental conditions on the same instrument and are similar in size and composition and any effects of DOF cancel out when $E_{50}(n c)$ is expressed in \% of $E_{50}(c)$ (Figure $2 b$ ), we can draw some solid conclusions from our data. The $E_{50}$ values in Figure $2 \mathrm{~b}$ show that $\mathrm{HB}$ interactions interfere with $\mathrm{PT}$ within intermolecular salt bridges, ${ }^{35}$ from the ligand guanidinium group to a deprotonated phosphodiester moiety of the RNA, and subsequent ligand dissociation in an additive manner. Schmuck and coworkers observed similar behavior in aqueous solution where the stability of complexes between guanidinium derivatives and dipeptide carboxylates was found to increase with increasing number of $\mathrm{HBs}$ between the binding partners. ${ }^{50,51}$

The linear fit function in Figure $2 \mathrm{~b}$ extrapolates to $13.5 \mathrm{HB}$ donor atoms at $100 \%$, where $E_{50}(n c)$ is equal to $E_{50}(c)$, which is just below the $14 \mathrm{HB}$ donor atoms of RR. However, the fit is to data for ligands with a single guanidinium group, and as discussed above, gaseous $(\mathrm{RR}+\mathrm{H})^{+}$has a zwitterionic structure in which both guanidine side chains are protonated (Scheme 1); in $(\mathrm{GR}+\mathrm{H})^{+},(\mathrm{VR}+\mathrm{H})^{+}$, and $(\mathrm{KR}+\mathrm{H})^{+}$, the only charged site is the guanidinium group. ${ }^{44}$ Thus, for $R R$, $E_{50}(n c)$ is probably far higher than $E_{50}(c)$, which is also indicated by the presence of fragments with $R R$ attached at energies of up to $66 \mathrm{eV}$ (Figure S4). For the ligands with a single guanidinium group, each hydrogen bond increased the stability of the RNA-ligand interaction by an average of $8.6 \%$ relative to $E_{50}(c)$. Assuming that $E_{50}(c)$ is close to the energy for hydrolysis of $2^{\prime}, 3^{\prime}$-ribose cyclic phosphate by $\mathrm{CH}_{3} \mathrm{OH}$ $(\sim 225 \mathrm{~kJ} / \mathrm{mol}){ }^{43}$ the average stabilization per $\mathrm{HB}$ would be $\sim 20 \mathrm{~kJ} / \mathrm{mol}$, which is typical for HBs in the gas phase. ${ }^{30,32,33}$

To address the effect of RNA structure on ligand binding, we determined $E_{50}$ values for RNAs 1-7 in complexes with VR and RR (Figure 3a and Figure S9). Neither $E_{50}(n c)$ nor $E_{50}(c)$ showed a clear correlation with RNA sequence, composition,
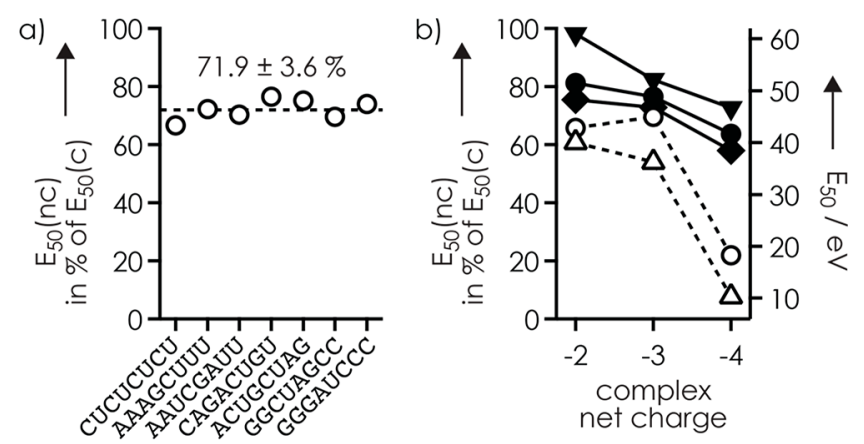

Figure 3. $E_{50}(n c)$ in $\%$ of $E_{50}(c)(O)$ for (a) complexes of VR and RNAs 1-7 with a net charge of -3 (the line indicates the average), and (b) the complex of VR and RNA 1 (left axis) versus net charge (also shown are $E_{50}(c)(\boldsymbol{\nabla}, \mathrm{RNA}+\mathrm{VR} ; \boldsymbol{\bullet}, \mathrm{RNA}+\mathrm{Tma} ; \boldsymbol{\vee}, \mathrm{RNA})$ and $E_{50}(n c)(\triangle$, RNA + VR) values in $\mathrm{eV}$ (right axis).

or possible secondary structure (Table 1), which indicates unspecific binding to phosphodiester moieties in nonhairpin structures without significant differences in stabilization by nucleobase interactions. Consistent with unspecific binding, the $c$ and $y$ fragments with VR and RR attached revealed binding to the phosphodiester moieties of residues 3 and 4 of RNAs 1-7 (Figure S10), just like Tma. Finally, we have studied the effect of net charge on complex stability. For both RNA 1 and its complexes with Tma and VR, the $E_{50}(c)$ values decreased nearly linearly with increasing charge (Figure $3 \mathrm{~b}$ ). A similar decrease was observed for the $E_{50}(n c)$ values for VR at -2 and -3 , but that at -4 was substantially lower, such that $E_{50}(n c)$ in $\%$ of $E_{50}(c)$ was similar at -2 and $-3,65.7 \pm 0.3 \%$ and $69.6 \pm 0.2 \%$, but only $22.0 \pm 0.1 \%$ at -4 . This can be rationalized by more facile $\mathrm{PT}$ and/or fewer hydrogen bonds in more extended structures at $-4(0.5$ charges $/ \mathrm{nt})$ compared to that at lower net charge $(0.25$ and 0.375 charges $/ n t$ at -2 and -3 , respectively).

\section{CONCLUSIONS}

In conclusion, we show that the interactions between Tma or $(\mathrm{RR}+\mathrm{H})^{+}$and deprotonated RNA are strong enough to survive RNA backbone cleavage by CAD. By contrast, salt bridges between ligands with a single guanidinium group and RNA anions convert into far weaker hydrogen bonds, followed by loss of ligand, at energies that are sufficiently high for RNA backbone cleavage unless the RNA-ligand interaction is stabilized by additional hydrogen bonds. For complexes of different 8 nt RNA with di- and tripeptide ligands with a single arginine residue and a net charge of -3 , additional stabilization by $>13$ hydrogen bonds increases the strength of the noncovalent interactions beyond that of the covalent RNA backbone bonds. Moreover, our data reveal similar stability of complexes with $0.25-0.375$ charges/nt, but substantially reduced stability at 0.5 charges/nt. Because net charge can easily be adjusted by the use of ESI additives, ${ }^{52}$ probing ligand binding sites in RNA by top-down $\mathrm{MS}^{10}$ should be possible even for very small peptides or other basic ligands such as aminoglycosides. Importantly, our study is a major step toward rationalizing the contributions of individual noncovalent interactions to the overall stability of gaseous biomolecular complexes, and toward resolving the ongoing controversy of whether or not native top-down mass spectrometry can provide reliable information on binding interfaces. 


\section{ASSOCIATED CONTENT}

\section{S Supporting Information}

The Supporting Information is available free of charge on the ACS Publications website at DOI: 10.1021/acs.analchem.8b05387.

Site-specific and overall yields of CAD products and fragment occupancies with ligands; $E_{50}(c), E_{50}(n c)$, and DOF values; structures of protonated ligands with hydrogen bond donor atoms (PDF)

\section{AUTHOR INFORMATION}

\section{Corresponding Author}

*E-mail: kathrin.breuker@uibk.ac.at.

\section{ORCID $\odot$}

Kathrin Breuker: 0000-0002-4978-0883

\section{Author Contributions}

The manuscript was written through contributions of all authors. All authors have given approval to the final version of the manuscript.

\section{Notes}

The authors declare no competing financial interest.

\section{ACKNOWLEDGMENTS}

This work was supported by the Austrian Science Fund (FWF; P27347 and P30087 to K.B.) and the Austrian Research Promotion Agency (FFG; West-Austrian BioNMR). Funding for open access charge: Austrian Science Fund (FWF).

\section{REFERENCES}

(1) Marcoux, J.; Robinson, C. V. Structure 2013, 21, 1541-1550.

(2) Lossl, P.; van de Waterbeemd, M.; Heck, A. J. R. EMBO J. 2016,

35, 2634-2657.

(3) Breuker, K. Nat. Chem. 2018, 10, 114-116.

(4) Breuker, K.; McLafferty, F. W. Proc. Natl. Acad. Sci. U. S. A. 2008, 105, 18145-18152.

(5) Polfer, N. C.; Oomens, J. Mass Spectrom. Rev. 2009, 28, 468494.

(6) Lanucara, F.; Holman, S. W.; Gray, C. J.; Eyers, C. E. Nat. Chem. 2014, 6, 281-294.

(7) Rizzo, T. R.; Boyarkin, O. V. In Gas-Phase IR Spectroscopy and Structure of Biological Molecules; Rijs, A.M., Oomens, J., Eds.;Springer: 2015; pp 43-97.

(8) Servage, K. A.; Silveira, J. A.; Fort, K. L.; Russell, D. H. Acc. Chem. Res. 2016, 49, 1421-1428.

(9) Li, H.; Nguyen, H. H.; Loo, R. R. O.; Campuzano, I. D. G.; Loo, J. A. Nat. Chem. 2018, 10, 139.

(10) Schneeberger, E. M.; Breuker, K. Angew. Chem., Int. Ed. 2017, $56,1254-1258$.

(11) Skinner, O. S.; Haverland, N. A.; Fornelli, L.; Melani, R. D.; Do Vale, L. H. F.; Seckler, H. S.; Doubleday, P. F.; Schachner, L. F.; Srzentic, K.; Kelleher, N. L.; Compton, P. D. Nat. Chem. Biol. 2017, $14,36-41$.

(12) Lai, L. B.; Tanimoto, A.; Lai, S. M.; Chen, W. Y.; Marathe, I. A.; Westhof, E.; Wysocki, V. H.; Gopalan, V. Nucleic Acids Res. 2017, 45, $7432-7440$

(13) Ma, X.; Lai, L. B.; Lai, S. M.; Tanimoto, A.; Foster, M. P.; Wysocki, V. H.; Gopalan, V. Angew. Chem., Int. Ed. 2014, 53, 1148311487.

(14) Saliou, J. M.; Manival, X.; Tillault, A. S.; Atmanene, C.; Bobo, C.; Branlant, C.; Van Dorsselaer, A.; Charpentier, B.; Cianferani, S. Proteomics 2015, 15, 2851-2861.

(15) van Duijn, E.; Barbu, I. M.; Barendregt, A.; Jore, M. M.; Wiedenheft, B.; Lundgren, M.; Westra, E. R.; Brouns, S. J.; Doudna, J.
A.; van der Oost, J.; Heck, A. J. Mol. Cell. Proteomics 2012, 11, 14301441.

(16) Delvaux, D.; Murty, M. R.; Gabelica, V.; Lakaye, B.; Lunin, V. V.; Skarina, T.; Onopriyenko, O.; Kohn, G.; Wins, P.; De Pauw, E.; Bettendorff, L. J. Biol. Chem. 2011, 286, 34023-34035.

(17) Fabris, D. Anal. Chem. 2011, 83, 5810-5816.

(18) Fabris, D.; Turner, K. B.; Kohlway, A. S.; Hagan, N. A. Biopolymers 2009, 91, 283-296.

(19) Alves, S.; Woods, A.; Tabet, J. C. J. Mass Spectrom. 2007, 42, $1613-1622$.

(20) Schennach, M.; Schneeberger, E. M.; Breuker, K. J. Am. Soc. Mass Spectrom. 2016, 27, 1079-1088.

(21) Yin, S.; Xie, Y. M.; Loo, J. A. J. Am. Soc. Mass Spectrom. 2008, 19, 1199-1208.

(22) Yin, S.; Loo, J. A. J. Am. Soc. Mass Spectrom. 2010, 21, 899907.

(23) Schulze-Gahmen, U.; Echeverria, I.; Stjepanovic, G.; Bai, Y.; Lu, H. S.; Schneidman-Duhovny, D.; Doudna, J. A.; Zhou, Q.; Sali, A.; Hurley, J. H. eLife 2016, 5, e15910.

(24) Patel, D. J. Curr. Opin. Struct. Biol. 1999, 9, 74-87.

(25) Borkar, A. N.; Bardaro, M. F.; Camilloni, C.; Aprile, F. A.; Varani, G.; Vendruscolo, M. Proc. Natl. Acad. Sci. U. S. A. 2016, 113, $7171-7176$.

(26) Thurlkill, R. L.; Grimsley, G. R.; Scholtz, J. M.; Pace, C. N. Protein Sci. 2006, 15, 1214-1218.

(27) Grimsley, G. R.; Scholtz, J. M.; Pace, C. N. Protein Sci. 2008, $18,247-251$.

(28) Brown, W. H.; Iverson, B. L.; Anslyn, E. V.; Foote, C. S. Organic Chemistry, 7th ed.; Cengage Learning, Boston, 2014.

(29) Schennach, M.; Breuker, K. Angew. Chem., Int. Ed. 2014, 53, 164-168.

(30) Meot-Ner, M. Chem. Rev. 2012, 112, PR22-PR103.

(31) Rodgers, M. T.; Armentrout, P. B. Chem. Rev. 2016, 116, $5642-5687$.

(32) BenTal, N.; Sitkoff, D.; Topol, I. A.; Yang, A. S.; Burt, S. K.; Honig, B. J. Phys. Chem. B 1997, 101, 450-457.

(33) Zeegers-Huyskens, T. J. Mol. Struct.: THEOCHEM 1986, 135, 93-103.

(34) Heiles, S.; Cooper, R. J.; Berden, G.; Oomens, J.; Williams, E. R. Phys. Chem. Chem. Phys. 2015, 17, 30642-30647.

(35) Vusurovic, J.; Schneeberger, E. M.; Breuker, K. ChemistryOpen 2017, 6, 739-750.

(36) Taucher, M.; Rieder, U.; Breuker, K. J. Am. Soc. Mass Spectrom. 2010, 21, 278-285.

(37) Kosutic, M.; Jud, L.; Da Veiga, C.; Frener, M.; Fauster, K.; Kreutz, C.; Ennifar, E.; Micura, R. J. Am. Chem. Soc. 2014, 136, 66566663.

(38) Hofacker, I. L. Nucleic Acids Res. 2003, 31, 3429-3431.

(39) Riml, C.; Glasner, H.; Rodgers, M. T.; Micura, R.; Breuker, K. Nucleic Acids Res. 2015, 43, 5171-5181.

(40) Jellen, E. E.; Chappell, A. M.; Ryzhov, V. Rapid Commun. Mass Spectrom. 2002, 16, 1799-1804.

(41) Mavri, J.; Vogel, H. J. Proteins: Struct., Funct., Genet. 1994, 18, 381-389.

(42) Ribeiro, A. J. M.; Ramos, M. J.; Fernandes, P. A. J. Chem. Theory Comput. 2010, 6, 2281-2292.

(43) Lopez, X.; Dejaegere, A.; Leclerc, F.; York, D. M.; Karplus, M. J. Phys. Chem. B 2006, 110, 11525-11539.

(44) Prell, J. S.; O’Brien, J. T.; Steill, J. D.; Oomens, J.; Williams, E. R. J. Am. Chem. Soc. 2009, 131, 11442-11449.

(45) Hunter, E. P.; Lias, S. G. In NIST Chemsitry WebBook, NIST Standard Reference Database Number 69; Linstrom, P. J., Mallard, W. G., Eds.: National Institute of Standards and Technology: Gaithersburg, MD, http://webbook.nist.gov, retrieved September 6, 2018.

(46) Harrison, A. G. Int. J. Mass Spectrom. 2001, 210, 361-370.

(47) Harrison, A. G.; Young, A. B. Int. J. Mass Spectrom. 2006, 255, 111-122. 
(48) Rodgers, M. T.; Armentrout, P. B. Mass Spectrom. Rev. 2000, $19,215-247$.

(49) Demireva, M.; Williams, E. R. J. Am. Soc. Mass Spectrom. 2010, 21, 1133-1143.

(50) Schmuck, C. Chem. - Eur. J. 2000, 6, 709-718.

(51) Schmuck, C.; Geiger, L. J. Am. Chem. Soc. 2004, 126, 88988899.

(52) Ganisl, B.; Taucher, M.; Riml, C.; Breuker, K. Eur. J. Mass Spectrom. 2011, 17, 333-343. 